УДК 621.1

\title{
The Far East Cogeneration Development
}

\author{
Dmitriy R. Bibikov, Konstantin A. Shtym, \\ Pavel A. Bayankin and Alexander A. Umnov* \\ Far Eastern Federal University \\ Vladivostok, Russian Federation
}

Received 06.12.2019, received in revised form 16.01.2020, accepted 19.02.2020

\begin{abstract}
This article considers the heat and power supply system based on small and mediumsized cogeneration at the "Vostochnaya" combined heat - and - power plant (GTU - CHPP "Vostochnaya" in Vladivostok) and the "Yuzhno-Sakhalinskaya" CHPP-1 (power units 4 and 5 of the GTU in Yuzhno-Sakhalinsk). This cogeneration is aimed at developing the southern region of the Far East and boosting its energy capacity. The article describes the main equipment such as General Electric LM6000 gas turbine units installed at the GTU - CHPP "Vostochnaya" and at power units 4, 5 of the GTU in "Yuzhno-Sakhalinskya" CHPP-1. Heat energy consumption during the heating period of 2018-2019 at "Vostochnaya" was 787.5 thousand Gcal. The specific reference fuel consumption for electric generation was $230 \mathrm{~g} / \mathrm{kWh}$, for heat supply $-121.9 \mathrm{~kg} / \mathrm{Gcal}$. Heat energy consumption during the heating period of 2018 at the power units 4 and 5 of the GTU in "Yuzhno-Sakhalinskaya" CHPP-1 was 321.59 Gcal. The specific reference fuel consumption for electric generation was $296.1 \mathrm{~g} / \mathrm{kWh}$, for heat supply $-124.7 \mathrm{~kg} / \mathrm{Gcal}$. Despite the underutilization of GTU - CHPP "Vostochnaya" in terms of electric and thermal energy (the consumption volumes of connected consumers are less than the design loads), the equivalent fuel consumption indicators reflect the efficiency of GTU generating equipment.
\end{abstract}

Keywords: GTU, CHPP, SFC, HPC, LPC, HPT, LPT, CC, WHB, PB.

Citation: Bibikov D.R., Shtym K.A., Bayankin P.A., Umnov A.A. The Far East cogeneration development, J. Sib. Fed. Univ. Eng. \& Technol., 2020, 13(2), 213-232. DOI: 10.17516/1999-494X-0218

(C) Siberian Federal University. All rights reserved

This work is licensed under a Creative Commons Attribution-NonCommercial 4.0 International License (CC BY-NC 4.0).

* Corresponding author E-mail address: dibibikov@yandex.ru 


\title{
Развитие когенерации Дальнего Востока
}

\author{
Д.Р. Бибиков, К.А. Штым, \\ П.А. Баянкин, А.А. Умнов \\ Дальневосточный федеральный университет \\ Российская Федераџия, Владивосток
}

Аннотация. В данной статье рассмотрена система тепло- и электроснабжения на базе малой и средней когенерации, теплоэлектроцентрали «Восточная» (ГТУ-ТЭЦ «Восточная» г. Владивосток) и Южно-Сахалинской ТЭЦ-1 (4 и 5-й энергоблоки ГТУ, г. Южно-Сахалинск). Данная когенерация создана в рамках наращивания мощности и развития южного региона Дальнего Востока. Дано описание основного оборудования - газотурбинных установок General Electric LM6000, установленных на ГТУ-ТЭЦ «Восточная» и ГТУ 4,5-го энергоблоков Южно-Сахалинской ТЭЦ-1. Отпуск тепловой энергии за отопительный период 2018-2019 года ГТУ-ТЭЦ «Восточная» составил 787,5 тыс. Гкал. Удельный расход условного топлива на отпуск электроэнергии равен 230 г/кВт*ч, на отпуск тепла - 121,9 кг/Гкал. Отпуск тепловой энергии за отопительный период 2018 г. 4,5-го энергоблоков ГТУ Южно-Сахалинской ТЭЦ-1 составил 321,59 Гкал. Удельный расход условного топлива на отпуск электроэнергии был равен 296,1 г/кВт*ч, на отпуск тепла - 124,7 кг/Гкал. Несмотря на недозагрузку ГТУ-ТЭЦ «Восточная» по электрической и тепловой энергии (объемы потребления присоединенных потребителей меньше расчетных нагрузок), показатели расхода условного топлива свидетельствуют об эффективности генерирующего оборудования ГТУ.

Ключевые слова: ГТУ, ТЭЦ, УРУТ, КВД, КНД, ТВД, ТНД, КС, КУВ, ПВК.

Цитирование: Бибиков, Д.Р. Развитие когенерации Дальнего Востока / Д.Р. Бибиков, К.А. Штым, П.А. Баянкин, А.А. Умнов // Журн. Сиб. федер. ун-та. Техника и технологии, 2020. 13(2). С. 213-232. DOI: 10.17516/1999-494X-0218

\section{Введение}

История появления ТЭЦ «Восточная» берет свое начало в конце 60-х гг. прошлого века, когда на ее площадке работала угольная теплоцентраль. В конце 1970-х гг. теплоцентраль была закрыта по экологическим соображениям, а ее мощности заменены Центральной пароводяной бойлерной. В бойлерной для получения горячей воды использовали пар Владивостокской ТЭЦ-2, поступающий по паропроводу длиной 7 км. Такое решение имело очевидные недостатки: бойлерная не была независимым энергоисточником, а использование протяженного паропровода вело к значительным потерям тепла. Тем не менее Центральная пароводяная бойлерная эксплуатировалась более 30 лет, и после того как ее оборудование полностью выработало свой срок службы, было принято решение о создании нового энергоисточника [1].

Современная ТЭЦ «Восточная» - новый объект тепло- и электрогенерации, возведенный на месте старой котельной и заменяющий устаревшие мощности Центральной пароводяной бойлерной (ЦПВБ).

Мощность теплоэлектроцентрали «Восточная» составляет 139,5 МВт (мегаватт) электрической энергии и 421 Гкал/ч (гигакалорий/час) тепловой энергии в горячей воде и 11 Гкал/ч в паре. Проектная годовая выработка электрической энергии составляет 791 млн кВт*ч (киловатт*час), тепловой энергии - 1377 тыс. Гкал. В состав основного оборудования станции входят три газотурбинные установки (ГТУ) марки LM 6000 PF Sprint производства компании 
«General Electric», котлы-утилизаторы компании «ЭМАльянс», три водогрейных котла «Дорогобужкотломаш». Основным топливом является природный газ, резервным - мазут.

Станция обеспечивает подачу тепла и горячей воды потребителям первого и второго сетевых районов, а также подачу пара строительному заводу «Аврора». Кроме того, объект может обеспечить до 20 \% потребности города в электроэнергии. По расчетам специалистов, станция может подавать электроэнергию в более чем 50 тысяч квартир и снабдить теплом более 600 многоквартирных домов.

В работе проведен анализ работы оборудования ТЭЦ «Восточная» в 2018-2019 гг. Сначала дано описание основного и вспомогательного оборудования станции, характеристики котельного, турбинного, насосного оборудования, принципиальные тепловая и электрическая схемы.

Далее описаны характеристики, работа, достоинства и недостатки горелочных устройств, устанавливаемых на котлах КВ - ГМ - 116,3 - 150 (котел водогрейный - газомазутный - 116,3 150): РГМГ - 30, SAACKE DDZG, циклонно-вихревых предтопков.

Потом представлен анализ работы и графические зависимости характеристик котлов КВ ГМ - 116,3 - 150 ст. № 1, 2, 3, работающих на станции ТЭЦ «Восточная», анализ отпуска тепловой и электрической энергии за время работы станции.

Развитие инфраструктуры г. Владивостока к саммиту АТЭС (Азиатско-Тихоокеанское экономическое сотрудничество) 2012 г. началось со строительства объектов электро- и теплотехники. На острове Русском были введены в эксплуатацию мини-ТЭЦ общей электрической мощностью 51,8 МВт и тепловой 190,1 Гкал. Но необходимость в увеличении тепловой и электрической мощности на материке была актуальна, поэтому в 2012 г. Правительством РФ и РАО ЕЭС Востока было решено построить новую ТЭЦ на площадке действующей ЦПВБ с Nэ $=139,5$ МВт, Nт = 420 Гкал. В состав основного оборудования ТЭЦ входят пиковые водогрейные котлы КВГМ-116,3-150 и газотурбинные установки (ГТУ) LM6000 PF Sprint с утилизационными теплообменниками КУВ-46,5-140.

Основным назначением газотурбинных установок 5-го энергоблока является выдача электроэнергии в энергосистему ПАО «Сахалинэнерго» и регулирование покрытия пиков суточного графика электрических нагрузок в энергосистеме. В 2012 г. введен в эксплуатацию 5-й энергоблок, состоящий из двух ГТУ типа LM6000 PD Sprint, производства «General Electric», установленной мощностью 91,16 МВт. С 1 января 2015 г. приказом ПАО «Сахалинэнерго» принято в эксплуатацию оборудование 4-го энергоблока Южно-Сахалинской ТЭЦ-1.

4-й энергоблок стал весомым вкладом в развитие Сахалинской энергосистемы и повышение надежности электроснабжения. Ввод в эксплуатацию нового энергообъекта, наряду с работой 5-го энергоблока, позволил создать в изолированной островной энергосистеме необходимый резерв маневренной генерирующей мощности. Благодаря этому ремонты основного оборудования Южно-Сахалинской ТЭЦ-1 проходят без вынужденных ограничений в электроснабжении потребителей. Кроме того, создан запас генерирующей мощности, необходимой для роста промышленности региона, развития социальной сферы и производственного сектора.

На текущий момент приоритетными направлениями энергетической политики России являются рациональное использование и экономия энергии. Довольно закономерен тот факт, что в современных условиях рациональное использование энергетических ресурсов становится од- 
ним из определяющих факторов роста экономики и социального развития. Данный подход, позволяя при одинаковых уровнях энергообеспечения направлять высвобождающиеся ресурсы на другие, помогает достигать экономически важные цели.

Разработка и внедрение программ по рационализации использования энергетических ресурсов, а также определение потенциала энергосбережения с учетом условий функционирования основных технологических объектов для предприятий разной направленности основываются исключительно на анализе фактического состояния эффективности использования энергетических ресурсов. Такие данные получают в ходе комплексного энергетического обследования предприятий.

Объектом данного анализа являются технико-экономические показатели 4-го и 5-го энергоблоков Южно-Сахалинской ТЭЦ-1 и их влияние на экономичность станции. Для этого необходимо сравнить показатели УРУТ (удельный расход условного топлива), мощности и выработки до и после строительства инвестиционных проектов 5-го и 4-го энергоблоков.

\section{Основная часть}

LM 6000 (рис. 1) является двухвальным газотурбинным двигателем и конструктивно состоит из следующих сборочных единиц: блока входного направляющего аппарата (ВНА), 5-ступенчатого компрессора низкого давления (КНД), 14-ступенчатого компрессора высокого давления (КВД) с изменяемой геометрией, кольцевой камеры сгорания, 2-ступенчатой турбины высокого давления (ТВД), 5-ступенчатой турбины низкого давления (ТНД), блока раздаточного редуктора и вспомогательного оборудования.

Технические характеристики турбоагрегата представлены в табл. 1.

Ротор низкого давления (РНД) состоит из компрессора низкого давления и турбины низкого давления. Соединительный фланец для подключения к приводному валу генератора находится на передней части ротора низкого давления.

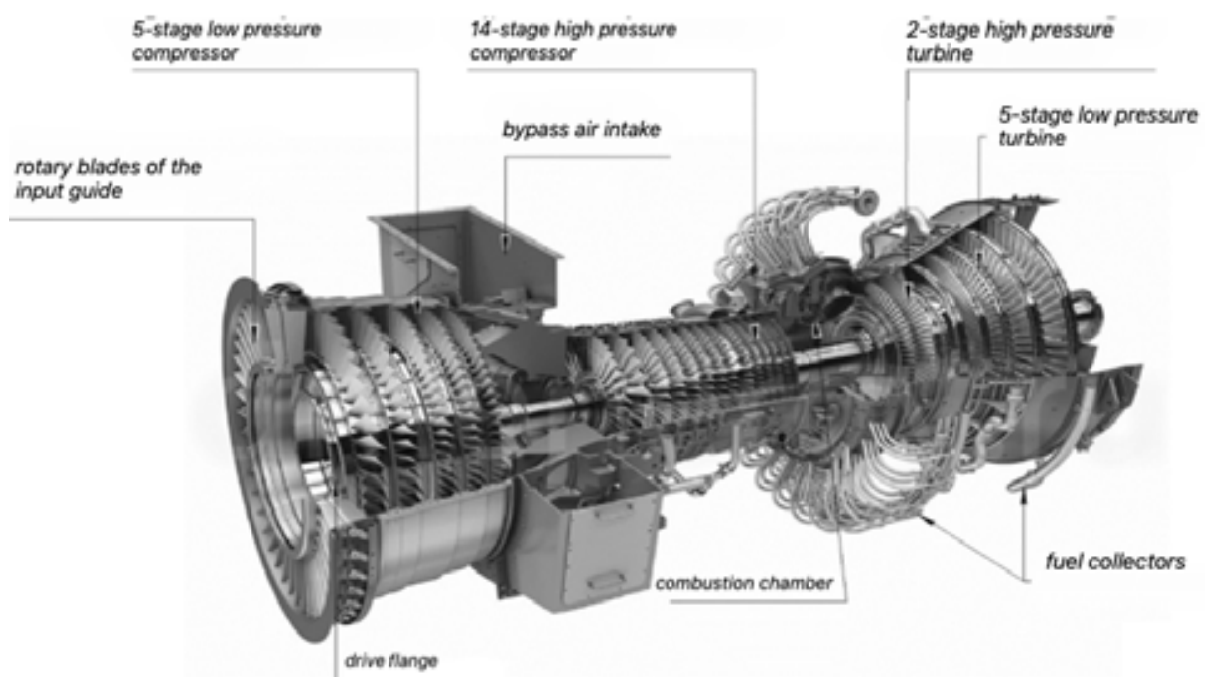

Рис. 1. Турбоагрегат LM 6000 PF Sprint

Fig. 1. Turbine unit LM 6000 PF Sprint 
Таблица 1. Технические характеристики турбоагрегата

Table 1. Turbine unit specifications

\begin{tabular}{|c|c|}
\hline Наименование & Значение \\
\hline Мощность, МВт & 46,5 \\
\hline Давление природного газа, МПа & 4,65 \\
\hline Температура воздуха на входе в КНД, ${ }^{\circ} \mathrm{C}$ & 15 \\
\hline Давление воздуха на входе в КНД, кПа & 101,3 \\
\hline Давление воздуха на входе в КВД, кПа & 190 \\
\hline Давление воздуха на выходе из КВД, кПа & 2570 \\
\hline Температура воздуха на выходе КВД, ${ }^{\circ} \mathrm{C}$ & 540 \\
\hline Температура газов на входе в ТВД, ${ }^{\circ} \mathrm{C}$ & 1200 \\
\hline Давление газов на входе в ТНД, кПа & 620 \\
\hline Температура газов на входе в ТНД, ${ }^{\circ} \mathrm{C}$ & 870 \\
\hline Расход топлива, м $^{3} / ч$ & 11200 \\
\hline Температура газов после ГТУ, ${ }^{\circ} \mathrm{C}$ & 486 \\
\hline КПД, \% & 40,9 \\
\hline
\end{tabular}

Ротор высокого давления состоит из компрессора высокого давления и турбины высокого давления. Компрессоры низкого и высокого давления приводятся во вращение соответственно турбинами низкого и высокого давления через концентрические приводные валы.

Компрессоры и приводящие их во вращение турбины образуют два кинематически не связанных между собой каскада - каскад низкого давления и каскад высокого давления. Турбина низкого давления также создает на роторе момент силы для привода во вращение электрического генератора.

Три структурные рамы обеспечивают подшипниковые опоры для двух роторов газотурбинного двигателя (ГТД). Направление вращения роторов ГТУ - по часовой стрелке, если смотреть со стороны генератора.

Принцип работы двигателя заключается в следующем: воздух поступает в компрессор низкого давления через ВНА, сжимается в соотношении примерно 2,4:1 и направляется в компрессор высокого давления, где происходит его дальнейшее сжатие. В режиме холостого хода и низкой нагрузки расход воздуха за КНД регулируется сбросными клапанами со сбросом воздуха в атмосферу, расположенными в канале между двумя компрессорами.

Степень сжатия КВД составляет примерно 12:1, а общий коэффициент сжатия газогенератора приблизительно равняется 30:1 относительно давления окружающей среды.

Воздушный поток КВД регулируется входными поворотными лопатками и пятью ступенями лопаток статора с переменным углом (изменяемой геометрией). Из компрессора высокого давления сжатый воздух поступает в камеру сгорания.

Воздух, поступающий в кольцевую камеру сгорания, смешивается с топливом из 30-ти топливных форсунок. При запуске двигателя зажигание топливовоздушной смеси производится воспламенителями. После того как горение становится устойчивым и поддерживается самостоятельно, воспламенитель выключается. Газообразные продукты сгорания из ка-

$$
-217-
$$


меры сгорания поступают в последовательно расположенные турбины высокого и низкого давления. В турбинах происходит преобразование энергии горячих газов в механическую работу.

Мощность, развиваемая турбиной высокого давления, используется для привода компрессора высокого давления, ТНД - для привода компрессора низкого давления и через понижающий редуктор электрического генератора. Выхлопные газы проходят через турбину низкого давления и через переходной диффузор попадают в уходящий газоход [2].

\section{1. Устройство и работа составных частей двигателя}

\section{1. Компрессор низкого давления}

Компрессор низкого давления служит для сжатия атмосферного воздуха и подачи его в компрессор высокого давления. Компрессор низкого давления LM6000 является 5-ступенчатым осевым компрессором. Выпускной поток компрессора низкого давления проходит через регулируемые антипомпажные сбросные клапаны, обеспечивая достаточный запас по срыву потока (помпажу) КНД при параметрах низкой мощности или при резких переменных режимах изменения мощности. Лопатки статора КНД фиксированной конфигурации.

Ротор компрессора низкого давления предназначен для превращения механической энергии, полученной от вращения турбиной низкого давления, в энергию воздушного потока, проходящего через компрессор, а также для передачи крутящего момента к генератору.

Индивидуальные диски ротора КНД используются на ступенях 0 и 1. Ступени 2-4 ротора компрессора низкого давления (РКНД) являются цельной катушкой. Лопатки 0-й ступени индивидуально удерживаются в продольных пазах диска соединением «ласточкин хвост» в цельном держателе лопаток. Лопатки 1-4-й ступеней КНД удерживаются в круговом пазе на диске 1-й ступени и на катушке 2-4-й ступеней. Свойства крепления лопатки позволяют производить замену отдельных лопаток.

Корпус статора ступеней 0-3 имеет горизонтальный разъем для облегчения замены лопаток. Для диагностической проверки без демонтажа статор имеет бороскопные отверстия, находящиеся на ступенях 1, 2 и 3. Лопатки статора 4-й ступени вмонтированы в переднюю раму. Все лопатки статора имеют бандаж.

\section{2. Компрессор высокого давления}

Компрессор высокого давления служит для окончательного сжатия воздуха, поступающего из КНД, и подачи его в камеру сгорания. КВД LM6000 РF является 14-ступенчатым осевым компрессором. Он включает ВНА и ступени 1-5 с регулируемым углом атаки, которые обеспечивают бесперебойное функционирование и высокую эффективность работы компрессора при запуске и в рабочем диапазоне. После 8 и 14-й ступеней КВД выполнены отборы с установленными на них противопомпажными клапанами, которые заведены в выхлоп турбины и предназначены для предотвращения помпажных явлений при пуске и малых нагрузках ГТ. Отбор воздуха из 7 и 11-й ступеней направляется на охлаждение и подпор масляных картеров подшипников двигателя.

Ротор турбокомпрессора высокого давления предназначен для превращения механической энергии, полученной от вращения ТВД, в энергию воздушного потока, проходящего через 
компрессор. Конструктивно ротор ТКВД представляет собой узел, объединяющий ротор КВД и ротор ТВД.

Ротор компрессора высокого давления состоит из 14-ступеней. Диск 2-й ступени и катушка 11-14 ступеней выполнены заодно с валом. Лопатки ступеней 1 и 2 индивидуально, а остальные лопатки удерживаются в кольцевом пазе на роторе соединением «ласточкин хвост». Эти свойства позволяют производить замену отдельных лопаток 1-й ступени без демонтажа ротора. Лопатки 1-й ступени имеют бандаж посередине для снижения вибрационного напряжения.

Статор КВД состоит из литого корпуса, в котором находятся лопатки статора компрессора. Направляющие лопатки входного направляющего аппарата и лопатки ступеней 1-5 могут поворачиваться вокруг оси своих монтажных креплений, чтобы варьировать высоту профилей в протоке компрессора. Лопатки остальных ступеней выполнены стационарными. Корпус имеет горизонтальный разъем для простоты монтажа и обслуживания.

\section{3. Камера сгорания}

Камера сгорания предназначена для получения и подачи в турбину высокого давления рабочего тела (смеси воздуха и продуктов сгорания) необходимых параметров. По конструкции камера сгорания встроенная, прямоточная кольцевого типа (рис. 2).

В ГТД используется система сгорания обедненной топливной смеси (система снижения выбросов окислов азота $\mathrm{NO}_{\mathrm{x}}$ сухого типа). Конфигурация одинарной кольцевой камеры сгорания позволяет работать с равномерным соотношением смешения топлива с воздухом во всем диапазоне работы ГТУ, минимизируя выбросы $\mathrm{NO}_{\mathrm{X}}$ даже на режиме низкой нагрузки.

Газовое топливо вводится в камеру сгорания через 75 предварительных смесителей, установленных в 30 модулях, которые образуют в ней три кольцевых зоны горения: внешнюю зону, регулирующую и внутреннюю зону.

Тройная усовершенствованная кольцевая камера сгорания предназначена для возможности уменьшения выбросов в атмосферу при запуске и работе на полной мощности. Тепловые экраны камеры сгорания изготовлены из однокристального сплава никеля. Газово-воздушные предварительные смесители установлены в технологических отверстиях тепловых экранов тройной камеры сгорания.

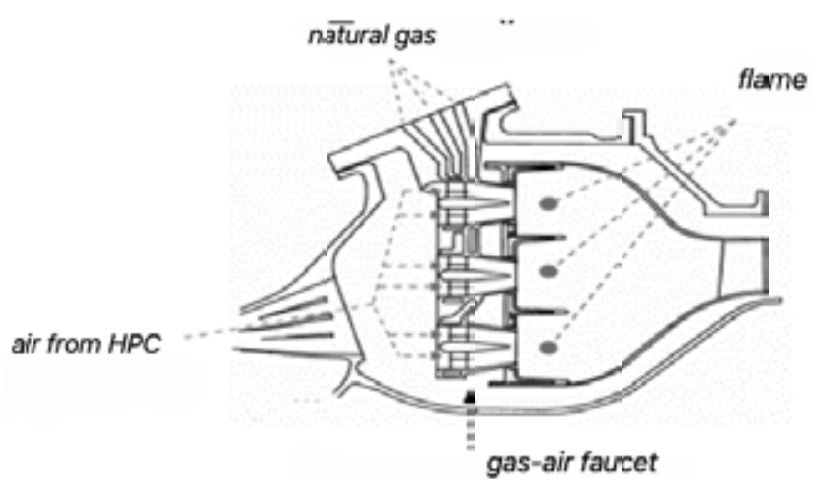

Рис. 2. Устройство камеры сгорания

Fig. 2. The device of the combustion chamber 


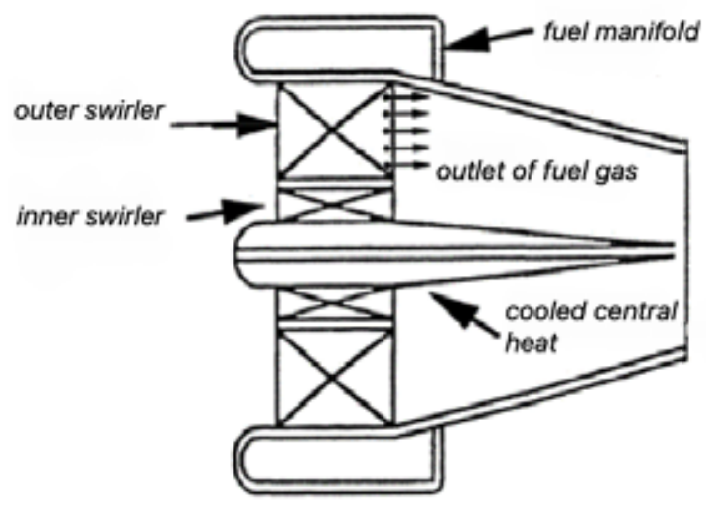

Рис. 3. Схема газовоздушного смесителя

Fig. 3. Scheme of gas-air faucet

В газовоздушном предварительном смесителе (рис. 3) воздух проходит через внутренний и наружный завихрители, закручивающие его поток в противоположных направлениях.

Получающийся турбулентный поток интенсивно смешивает газ и воздух. Обратную закрутку делают для устранения возможности формирования зон обратных токов в приосевой зоне смесителя. С этой же целью внутри смесителя размещают центральное тело. Газ из коллектора подается в закрученный воздушный поток через отверстия, расположенные на выходной кромке лопаток завихрителя. Остаточный вихрь на выходе из сопла смесителя помогает стабилизировать горение «бедной» предварительно перемешанной топливно-воздушной смеси за срезом сопла.

Система зажигания, состоящая из запальников, встроенных в камеру сгорания (КС), вырабатывает электрическую искру высокого напряжения, которая воспламеняет топливновоздушную смесь в КС при пуске. Система состоит из возбудителя зажигания, кабеля и искрового воспламенителя. После воспламенения горение поддерживается самостоятельно, без помощи воспламенителя.

\section{4. Турбина высокого давления}

Турбина высокого давления приводит во вращение компрессор высокого давления. Турбина высокого давления осевая, двухступенчатая. Каждая ступень образуется рядом сопловых лопаток, закрепленных в корпусе соплового аппарата, и следующим за ним рядом рабочих лопаток, закрепленных на диске ротора. В ТВД предусмотрено охлаждение воздухом наиболее горячих деталей и узлов.

\section{5. Турбина низкого давления}

Турбина низкого давления приводит во вращение КНД и генератор через понижающий редуктор, используя поток отработанного газа ТВД. Основными компонентами модуля турбины низкого давления являются пятиступенчатый статор, пятиступенчатый ротор, литая задняя рама турбины, поддерживающая корпус статора, и подшипники. 


\section{6. Подиипники}

Восемь подшипников (рис. 4) поддерживают вращающиеся компоненты в газотурбинном двигателе.

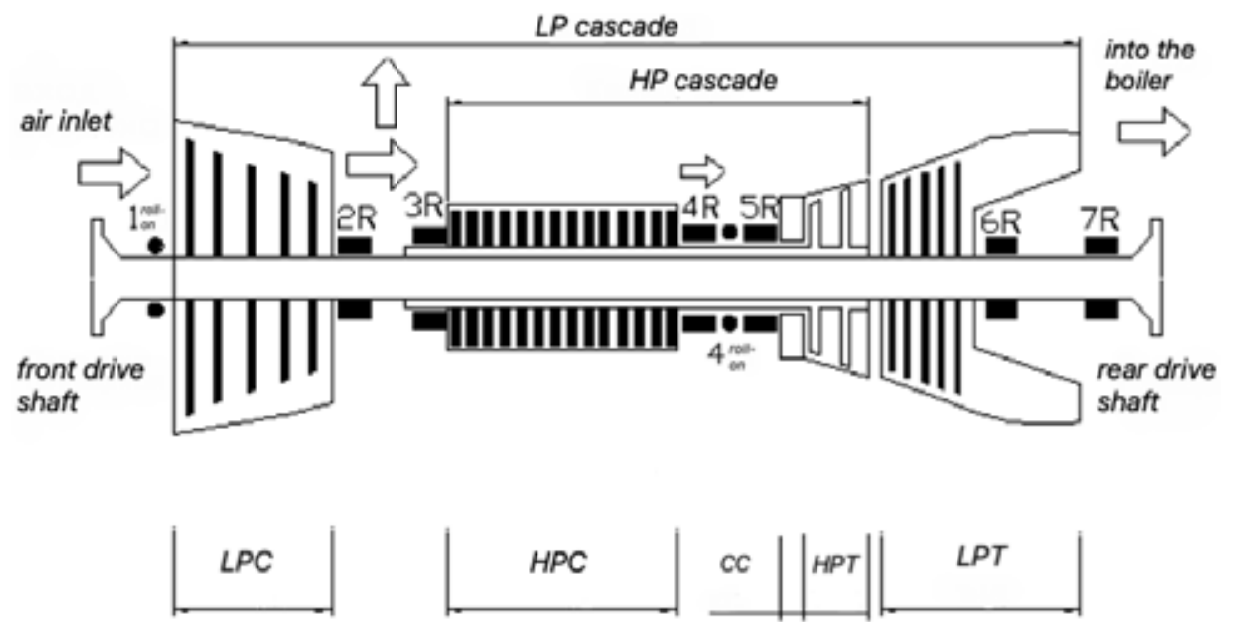

Рис. 4. Схема расположения подшипников ГТ

Fig. 4. Layout of bearings of the gas turbine

Каждая вращающаяся масса (компрессор, турбина и система разгрузочного поршня) поддерживается роликовыми подшипниками, а осевая нагрузка передается на шариковые подшипники. Все подшипники находятся в картерах опорных рам.

Лабиринтовые уплотнения предотвращают перетоки уплотняющего воздуха и масляных паров в картерах подшипников.

\section{7. Комплексное воздухоочистительное устройство (КВОУ) \\ и система вентиляции}

КВОУ (рис. 5) предназначено для эффективной очистки от пыли и атмосферных осадков воздуха, поступающего на охлаждение и вентиляцию отсеков ГТУ и на всос компрессора, обеспечивая защиту от эрозии лопаточного аппарата компрессора, снижение шума всоса до санитарных норм, защиту от обледенения воздухозаборного тракта путем подогрева воздуха во встроенных теплообменниках системы антиобледенения.

КВОУ рассчитано на использование в режиме непрерывной круглогодичной эксплуатации. Основные расчетные параметры КВОУ:

- расчетная пропуская способность, 9316 нм³/мин (нормальные кубометры/минута);

- расход воздуха в зону горения, $6513 \mathrm{Hм}^{3} / \mathrm{мин;}$

- расход воздуха вентиляции турбины, $1699 \mathrm{Hм}^{3} /$ мин;

- расход воздуха вентиляции генератора, $1104 \mathrm{Hм}^{3} / \mathrm{Mин;}$

- эффективность пылеулавливания не менее 99,9 \% частиц более 5 мкм (микрон);

- уровень звука на расстоянии не более 85 дБА (децибел).

$$
-221-
$$




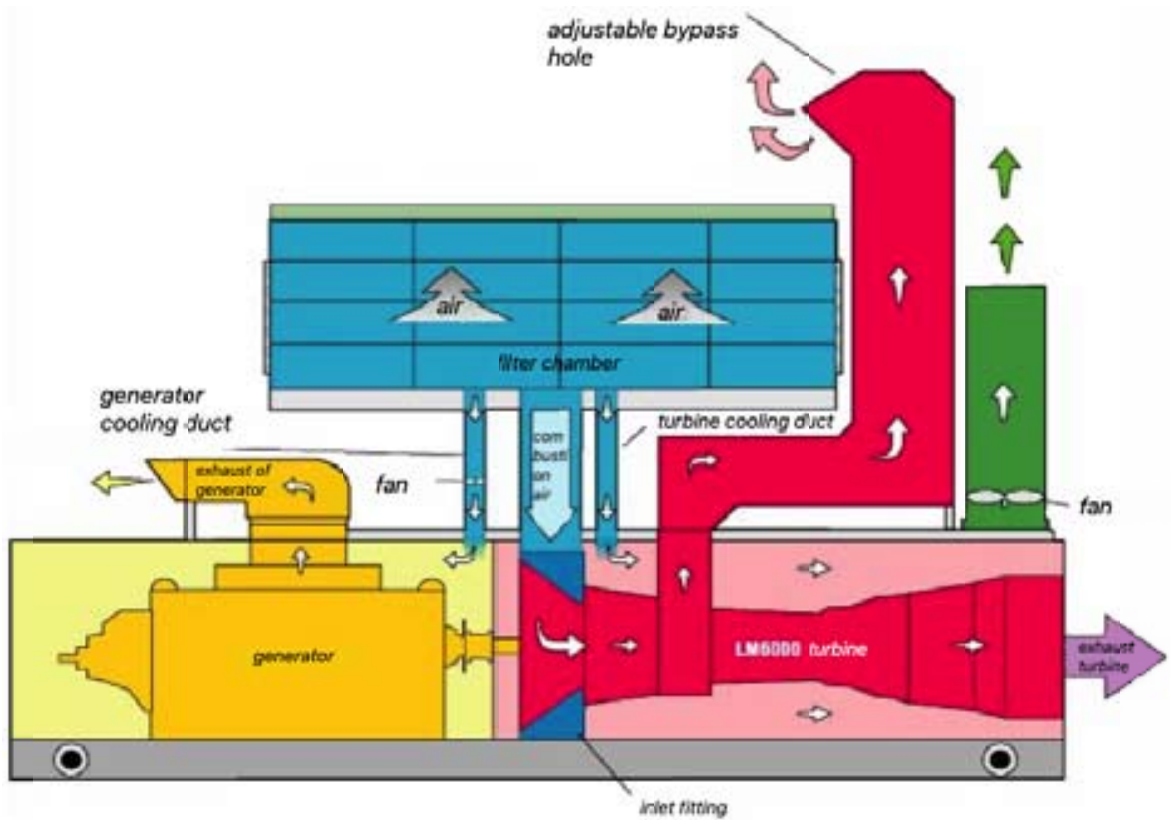

Рис. 5. Принципиальная схема вентиляции ГТУ

Fig. 5. Schematic diagram of the ventilation gas turbine

КВОУ представляет собой стальную блочную конструкцию, состоящую из двух одинаковых секций, каждая секция пропускает воздух встречными потоками и состоит из следующих основных узлов:

- входного сетчатого фильтра с защитными козырьками для защиты от осадков, крупного мусора и птиц;

- блока теплообменников антиобледенительной системы и влагоуловителя;

- блока элементов фильтров тонкой очистки;

- отсека чистого воздуха;

- входного шумоглушителя;

- воздуховодов;

- спиральной (улиточной) камеры впуска.

\section{8. Генератор}

Генератор двухполюсный, с воздушным охлаждением, напряжение 10500 В, 50 Гц, способен принимать полную нагрузку от газовой турбины в течение продолжительного времени при

Таблица 2. Технические характеристики генератора BDAX7-290ERJT

Table 2. Generator BDAX7-290ERJT specifications

\begin{tabular}{|c|c|c|c|c|}
\hline Завод изготовитель & $\begin{array}{c}\text { Полная мощность } \\
\mathrm{S}, \mathrm{MBA}\end{array}$ & $\begin{array}{c}\text { Активная } \\
\text { мощность Р, MBт }\end{array}$ & $\begin{array}{c}\text { Номинальное } \\
\text { напряжение U, кB }\end{array}$ & Ном. ток I, A \\
\hline BRUSH Electrical & 63,5 & 48,5 & 10,5 & 3334 \\
\hline
\end{tabular}




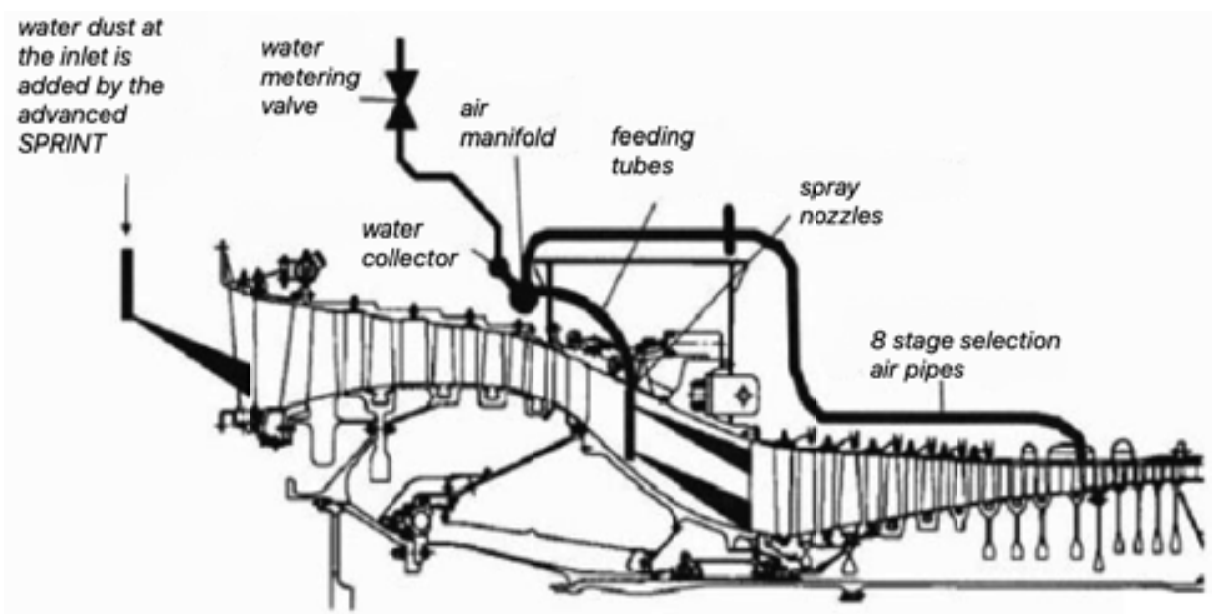

Рис. 6. Схема впрыска воды системы Sprint в ГТ

Fig. 6. Scheme of water injection Sprint system in gas turbine plant

любой температуре окружающей среды площадки в пределах рабочего диапазона. Генератор снабжен бесщеточной системой возбуждения с постоянным магнитом.

\section{9. Назначение и принции работы системы «Sprint»}

Система «Sprint» (Spray Intercooling - промежуточное охлаждение методом распыления жидкости) (рис. 6) повышает мощность турбины за счет впрыска воды для охлаждения воздуха в компрессоре, что значительно увеличивает массовый расход воздуха через компрессор.

Система основана на очень мелком распылении воды в проточную часть компрессора через форсунки, расположенные перед КВД и перед КНД. Мелкий распыл воды осуществляется за счет энергии сжатого воздуха, взятого после восьмой ступени компрессора высокого давления. Расход воды контролируется специальной программой управления двигателем, которая определяет место впрыска воды в зависимости от температуры воздуха на входе в турбину.

\section{2. Техническое описание основного и вспомогательного котельного оборудования}

Водогрейный стационарный котел (рис. 7) теплопроизводительностью 116,3 МВт (100 Гкал/ч) предназначен для получения горячей воды давлением до 2,1 МПа $(21,5$ кгс/см²) и номинальной температурой $150{ }^{\circ} \mathrm{C}$, используемой в системах отопления, вентиляции и горячего водоснабжения промышленного и бытового назначения, а также для технологических целей [3].

Котел работает на природном газе и мазуте при установленной тяге в основном или пиковом режиме. Технические характеристики котлоагрегата представлены в табл. 3.

Водогрейные котлы КВ-ГМ-116,3 выполнены по П-образной схеме и могут быть использованы как в основном $\left(70 \div 150{ }^{\circ} \mathrm{C}\right)$, так и пиковом $\left(100 \div 150{ }^{\circ} \mathrm{C}\right)$ режимах. Котлы могут также подогревать воду до $200{ }^{\circ} \mathrm{C}$. 

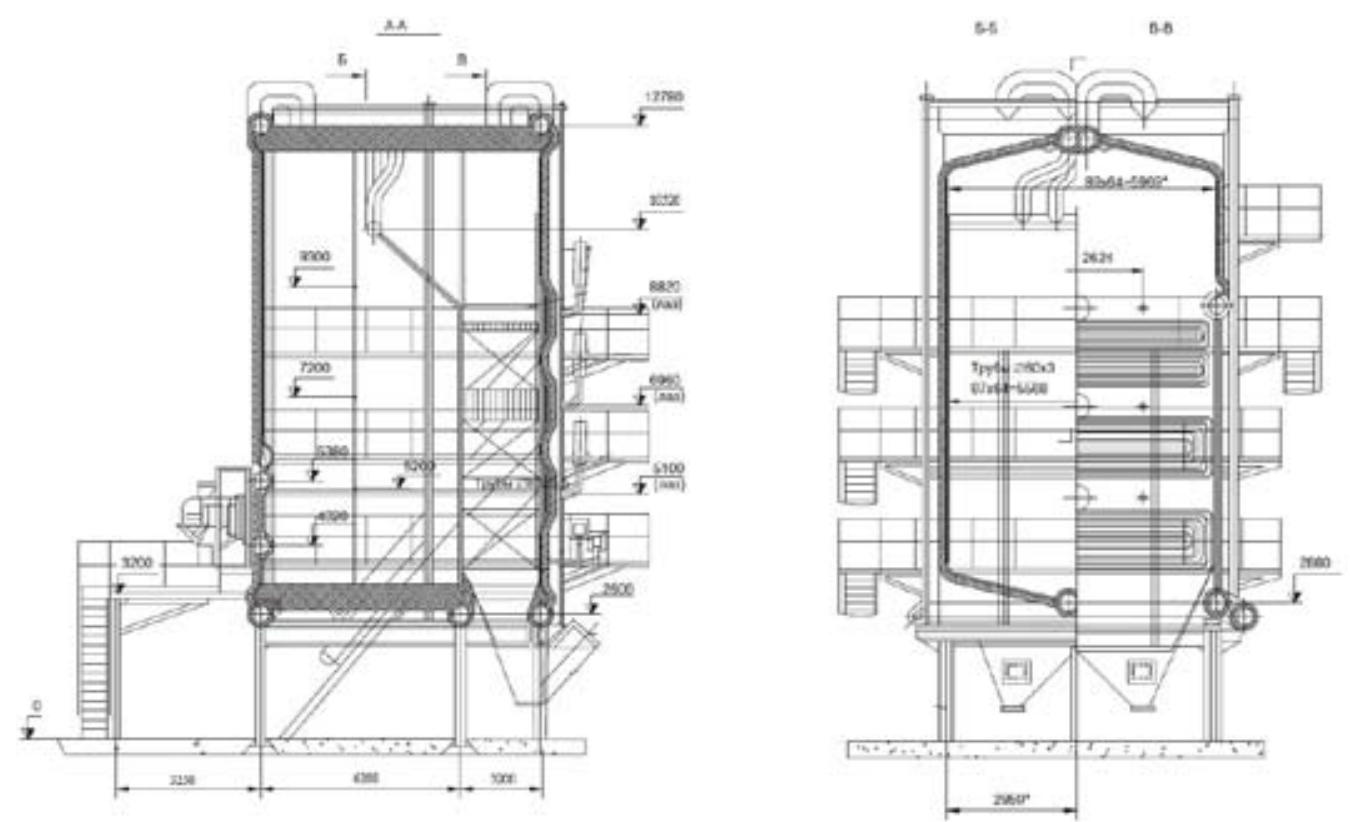

Рис. 7. Котел КВ - ГМ - 116,3 - 150

Fig. 7. Boiler BW - GO - 116,3-150

Котлы состоят из топочной камеры и конвективной шахты. Топочная камера котлов и задняя стена конвективной шахты закрыты экранами из труб Ø 60х3 мм. Конвективная поверхность нагрева котлов состоит из трех пакетов, набираемых из U-образных ширм, выполненных из труб Ø 28х3 мм.

Фронтальный экран снабжен коллекторами: верхним, нижним и двумя промежуточными, между которыми находятся кольца для формирования амбразур газомазутных горелок. Боковые стены конвективной шахты закрыты трубами Ø 83х3,5 мм, служащими стояками для ширм [4].

Продукты горения, покидающие топочную камеру через проход между задним экраном и потолком топочной камеры, движутся сверху вниз через конвективную шахту. Котел оборудован взрывными предохранительными клапанами, установленными на потолке топочной камеры. Для удаления воздуха из трубной системы при заполнении котла водой на верхних коллекторах установлены воздушники. Нижние коллекторы фронтального и заднего экранов конвективной шахты опираются на портал котла. Опора, расположенная в середине нижнего коллектора задней стены топочной камеры, неподвижна. Вес боковых экранов топочной камеры передается на портал через фронтальный и задний экраны.

Подвод воды осуществляется во фронтовой экран, затем вода разводится по боковым экранам, после чего попадает в промежуточный экран и конвективную часть, а отвод воды осуществляется из заднего экрана.

Для борьбы с низкотемпературной сернокислотной и кислородной коррозией поверхностей нагрева при несении низких нагрузок предусмотрено повышение температуры стенки труб путем поддерживания температуры воды на входе в котел не менее $70{ }^{\circ} \mathrm{C}$ за счет смешения 
Таблица 3. Технические характеристики котла КВ - ГМ - 116,3 - 150

Table 3. Boiler BW - GO - 116,3 - 150 specifications

\begin{tabular}{|c|c|c|}
\hline Величина & $\begin{array}{c}\text { Единица } \\
\text { измерения }\end{array}$ & Значение \\
\hline Топливо основное и резервное & & $\begin{array}{l}\text { Природный газ/ } \\
\text { мазут }\end{array}$ \\
\hline Номинальная теплопроизводительность & МВт (Гкал/ч) & $116,3(100)$ \\
\hline Расчетное (избыточное) давление воды на входе в котел & 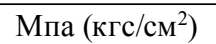 & $2,5(25,0)$ \\
\hline Рабочее (абсолютное) давление воды на выходе из котла & Мпа (кгс/см²) & $1,0(10,0)$ \\
\hline Температура воды на входе в котел: & \multirow{3}{*}{${ }^{\circ} \mathrm{C}$} & \\
\hline Основной режим & & 70 \\
\hline Пиковый режим & & 110 \\
\hline Температура воды на выходе из котла & ${ }^{\circ} \mathrm{C}$ & 150 \\
\hline Водяной объем & $\mathrm{M}^{3}$ & 30,5 \\
\hline $\begin{array}{l}\text { Диапазон регулирования теплопроизводительности по } \\
\text { отношению к номинальной }\end{array}$ & $\%$ & $20 \div 100$ \\
\hline $\begin{array}{l}\text { Максимально допустимое гидравлическое сопротивление котла } \\
\text { при номинальной производительности, не более }\end{array}$ & МПа (кге/см²) & $0,35(3,5)$ \\
\hline Расход воды через котел: & \multirow{3}{*}{$\mathrm{T} / \mathrm{\varphi}$} & \\
\hline Основной режим & & 1235 \\
\hline Пиковый режим & & 2460 \\
\hline Минимальный расход воды через котел при основном режиме & $\mathrm{T} / \mathrm{\varphi}$ & 1125 \\
\hline Конвективная поверхность нагрева & $\mathrm{M}^{2}$ & 2385 \\
\hline Радиационная поверхность нагрева (экраны) & $\mathbf{M}^{2}$ & 291,9 \\
\hline Температура уходящих газов при работе: & \multirow{3}{*}{${ }^{\circ} \mathrm{C}$} & \\
\hline На газе & & 131 \\
\hline На мазуте & & 171 \\
\hline КПД котла (брутто): & \multirow{3}{*}{$\%$} & \\
\hline На газе & & 93,2 \\
\hline На мазуте & & 91,8 \\
\hline \multicolumn{3}{|l|}{ Расход топлива: } \\
\hline газ $(\mathrm{QH})=8260$ ккал/м³ & $\mathrm{M}^{3} / \mathrm{\varphi}$ & 12500 \\
\hline мазут $(\mathrm{QH})=9170$ ккал/кг & Кг/ч & 11800 \\
\hline Удельный выброс оксидов азота (NOX) при О2 = 3 \%, не более: & \multirow{3}{*}{$\mathrm{M} \Gamma / \mathrm{HM}^{3}$} & \\
\hline На газе & & 100 \\
\hline На мазуте & & 200 \\
\hline Удельная концентрация СО, не более & $\mathrm{M \Gamma} / \mathrm{HM}^{3}$ & 50 \\
\hline
\end{tabular}

выходящей из котла воды с обратной сетевой водой, т. е. рециркуляцией горячей воды. Котел оборудован тремя промышленными комбинированными газомазутными горелками SAACKE DDZG, расположенными на двух уровнях на фронтовом экране котла (рис. 8, 9).

Горелки имеют два устройства:

a) для подачи газа от кольцевого коллектора горелки с раздачей на 8 газовых форсунок с разнонаправленными выходными каналами, установленными равномерно по периметру выходного сечения горелки; 


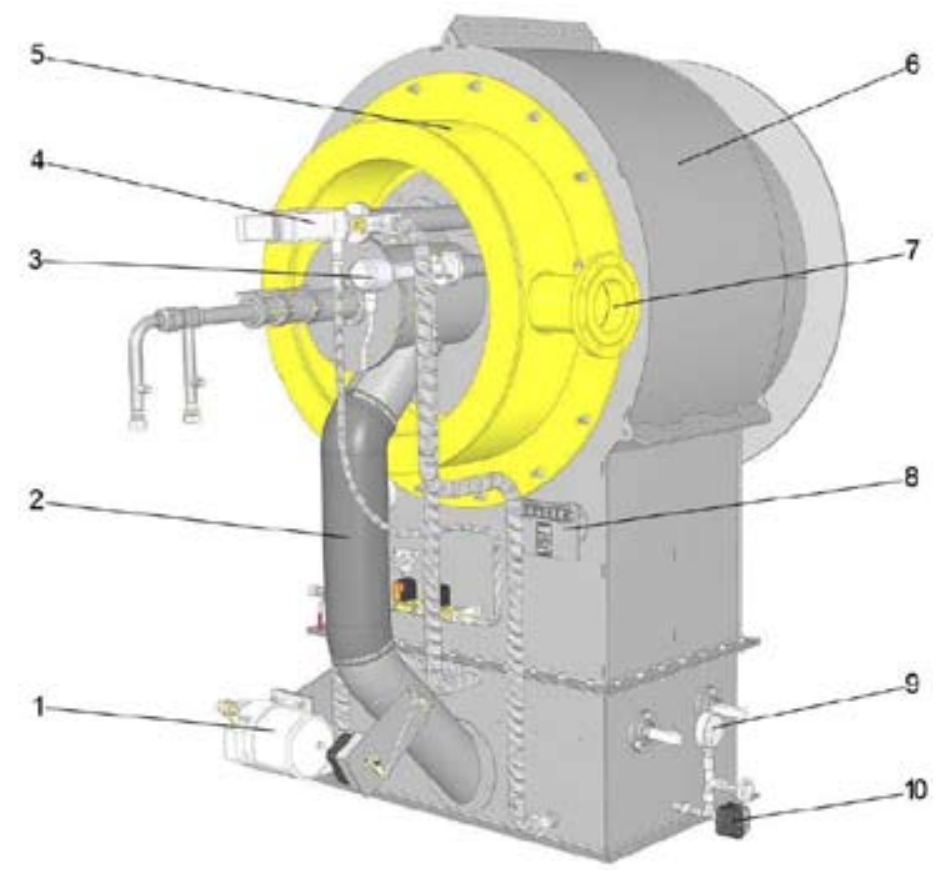

Рис. 8. Конструкция горелочного устройства SAACKE DDZG вид A: 1 - серводвигатель для регулирующих заслонок вторичного воздуха; 2 - линия первичного воздуха; 3 - датчик факела; 4 - запальник; 5 - газовое кольцо; 6 - воздухозаборник; 7 - вход основного газового топлива; 8 - фирменная табличка; 9 - манометр для измерения давления перед регулирующими заслонками вторичного воздуха; 10 - реле контроля давления воздуха

Fig. 8. SAACKE DSG burner design type A: 1 - servomotor for control dampers secondary air; 2 -primary airline; 3 -torch sensor; 4 - ignitor; 5 - gas ring; 6 - air intake; 7 - main gas fuel input; 8 -nameplate; 9 - pressure gauge for measuring control dampers secondary air; 10 - air pressure monitor

б) для подачи мазута и пара в паромеханическую форсунку, установленную в центре горелки. Данные горелки рассчитаны на раздельное сжигание мазута и природного газа. При этом каждая горелка оснащена газовой линией, представляющей собой блок газооборудования в виде участка газовой арматуры, обеспечивающей в автоматическом режиме розжиг и работу горелки на природном газе.

У двухтопливных горелок воздух для сжигания топлива перед регулирующими воздушными заслонками в блоке заслонок делится на первичный и вторичный, что позволяет регулировать оба потока независимо друг от друга. Поэтому у этих горелок установлено по одному серводвигателю, соответственно, для регулирующей заслонки первичного воздуха и регулирующих заслонок вторичного воздуха. Завихрение потока первичного воздуха создается внутри горелки, а вторичный воздух подается в топочную камеру без завихрения.

Поток основного газового топлива разделяется посредством расположенного внутри газового кольца на первичный и вторичный газ. Таким образом, количество первичного и вторичного воздуха регулируется совместно (в постоянном соотношении). Первичный и вторичный газ поступают по нескольким трубкам для ввода газа в топочную камеру.

Поток основного жидкого топлива (легкого или тяжелого) и распылительная среда (пар) регулируются в арматурном блоке жидкого топлива, на который имеется отдельная доку- 


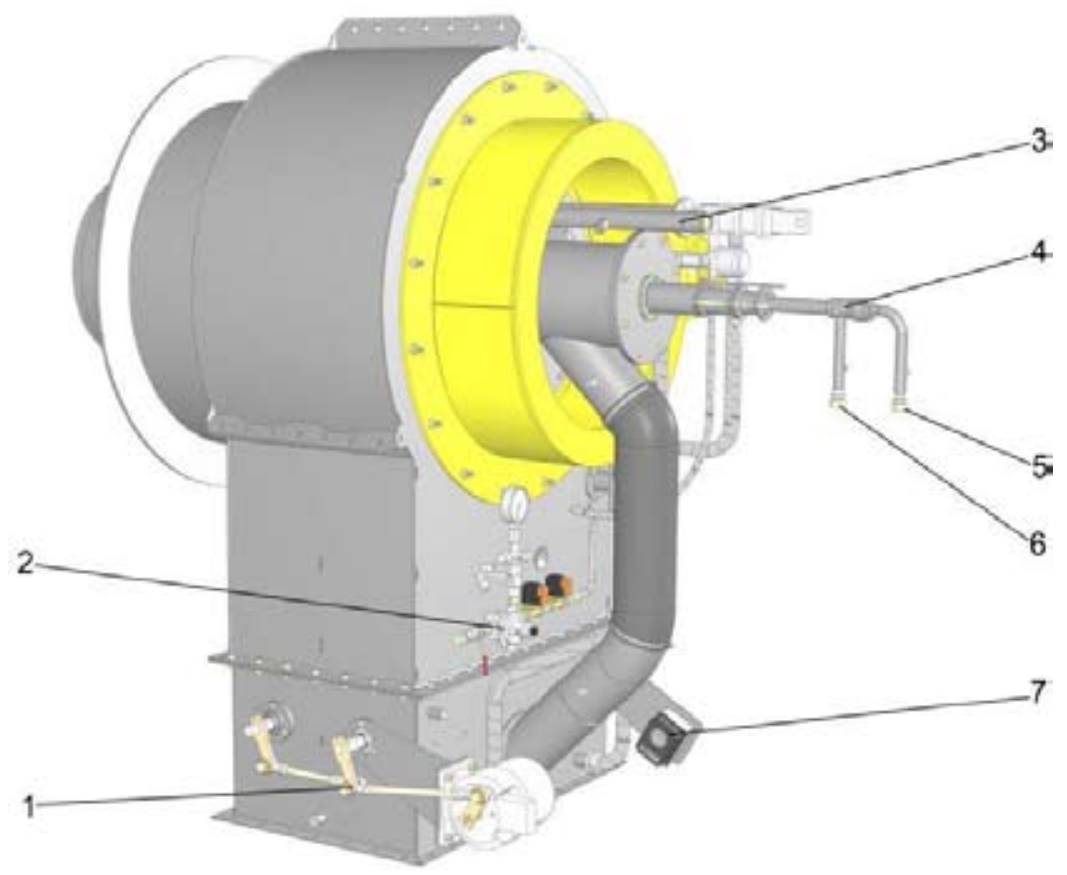

Рис. 9. Конструкция горелочного устройства SAACKE DDZG вид Б: 1 - приводные тяги для регулирующих заслонок вторичного воздуха; 2 - запальная арматура; 3 - смотровое окно; 4 - ствол мазутной форсунки; 5 - вход пара; 6 - вход мазута; 7 - серводвигатель для регулирующей заслонки первичного воздуха

Fig. 9. SAACKE DDZG burner design type B: 1 - drive rods for control dampers secondary air; 2 - ignitor fittings; 3 - viewing window; 4 - fuel oil nozzle barrel; 5 -steam entry; 6 - fuel oil input; 7 - servomotor for control dampers primary airline

ментация. После входа в горелку они поступают через трубку для ввода жидкого топлива в форсунку для жидкого топлива. Тонко распыленная смесь выходит из форсунки несколькими струями [4].

Зажигание основного факела происходит в запальнике со встроенной системой контроля факела (ионизация). Он горит в зоне обмуровки.

Тягодутьевая установка состоит из одного центробежного дымососа двухстороннего всасывания типа Д22х2 - 0,62 КГМ и одного центробежного вентилятора одностороннего всасывания типа ВГДН - 19,3К - 0,62.

\section{1. Котел-утилизатор}

Водогрейный котел-утилизатор КУВ - 46,4 - 130 (рис. 10) тепловой мощностью 40,0 Гкал/ч (46,4МВт) предназначен для нагрева сетевой воды системы отопления за счет утилизации тепла выхлопных газов газовой турбины типа LM6000PF Sprint.

Котел предназначен для применения в макроклиматических районах с умеренным и холодным климатом, в закрытом помещении. Выполнен однокорпусным, горизонтального типа, с принудительной циркуляцией, опирается на опорные конструкции и состоит из транспортабельных блоков, образующих при сборке газоплотный корпус. 


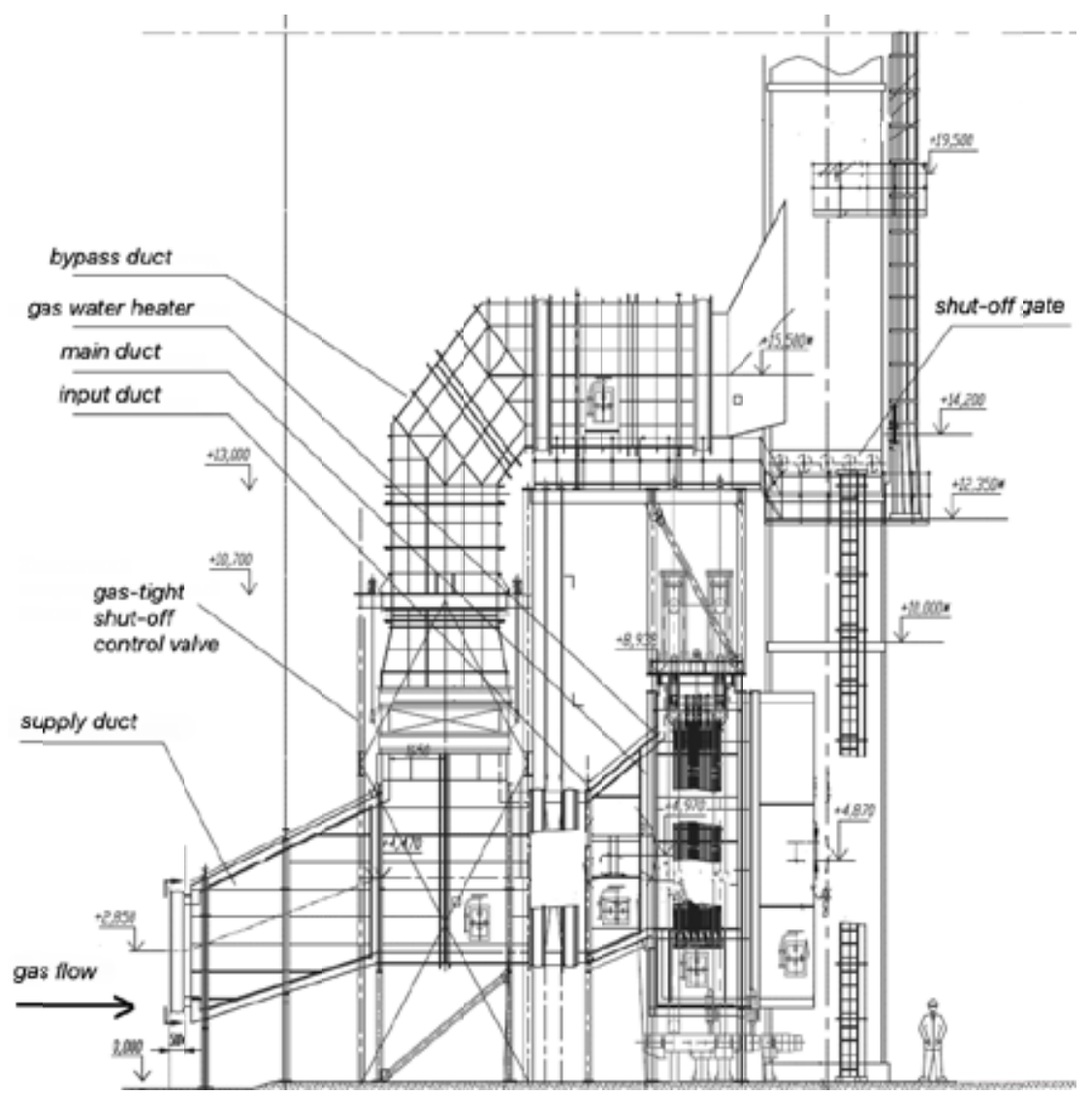

Рис. 10. Котел $-46,4-130$

Fig. 10. Boiler $-46,4-130$

Выхлопные газы из турбины с максимальной температурой $516{ }^{\circ} \mathrm{C}$ по горизонтальному газоходу направляются в КУВ, проходят его, отдавая тепло нагреваемой сетевой воде, и далее поступают в дымовую трубу. На подводящем и байпасном газоходах установлены газоплотные запорно-регулирующие клапаны. В дымовой трубе установлена дождевая заслонка и шумоглушитель.

Рабочий диапазон изменения нагрузки котла-утилизатора, в том числе и насосного оборудования, соответствует диапазону нагрузок ГТУ на 25-100 \%. Изменение нагрузки достигается изменением параметров газов на входе в котел.

Расчетные параметры при работе КУ в режимах для характерных температур наружного воздуха на продуктах сгорания природного газа приведены в табл. 4.

Поверхности нагрева котла-утилизатора выполнены из труб с наружным просечным спирально-ленточным оребрением. Трубы поверхностей нагрева размещаются в шахматном порядке для достижения оптимальной теплопередачи. Расположение секций блоков по глубине газохода выбрано с учетом параметров теплоносителя в секциях и оптимальных температурных напоров в поверхностях нагрева. Диаметр труб и расстояние между ними выбраны таким образом, чтобы обеспечить оптимальную теплопередачу и скорость среды в каждом пучке труб. 
Таблица 4. Расчетные параметры при работе котла-утилизатора на продуктах сгорания природного газа Table 4. Design parameters for boiler operation on natural gas combustion products

\begin{tabular}{|c|c|c|c|c|}
\hline Наименование & $\begin{array}{c}\text { Единица } \\
\text { измерения }\end{array}$ & \multicolumn{3}{|c|}{ Значение } \\
\hline Температура наружного воздуха & ${ }^{\circ} \mathrm{C}$ & -24 & 13,7 & 35 \\
\hline Нагрузка ГТ & $\%$ & \multicolumn{3}{|c|}{100} \\
\hline Температура воды на входе & ${ }^{\circ} \mathrm{C}$ & \multicolumn{3}{|c|}{70} \\
\hline Температура воды на выходе & ${ }^{\circ} \mathrm{C}$ & \multicolumn{3}{|c|}{130} \\
\hline Давление воды на выходе & МПа & \multicolumn{3}{|c|}{1,6} \\
\hline Тепловая мощность & MBT & 45,7 & 46,6 & 43,8 \\
\hline Температура уходящих газов & ${ }^{\circ} \mathrm{C}$ & \multicolumn{2}{|c|}{124} & 119 \\
\hline Падение давления по газовому тракту & мМ.в.ст & 242 & 229 & 177 \\
\hline Нагрузка ГТ & $\%$ & \multicolumn{3}{|c|}{50} \\
\hline Температура воды на входе & ${ }^{\circ} \mathrm{C}$ & \multicolumn{3}{|c|}{70} \\
\hline Температура воды на выходе & ${ }^{\circ} \mathrm{C}$ & \multicolumn{3}{|c|}{130} \\
\hline Давление воды на выходе & МПа & \multicolumn{3}{|c|}{1,6} \\
\hline Тепловая мощность & МBт & 35,1 & 36,1 & 35,6 \\
\hline Температура уходящих газов & ${ }^{\circ} \mathrm{C}$ & 108 & 106 & 105 \\
\hline Падение давления по газовому тракту & MM.в.cT & 105 & 96 & 87 \\
\hline
\end{tabular}

Газоход КУ состоит из следующих элементов, последовательно расположенных по ходу газов:

- подводящий газоход с компенсатором за выходным фланцем выхлопного патрубка ГТУ;

- байпасный газоход с установленным в нем газоплотным запорно-регулирующим клапаном. Байпасный газоход выполнен в виде квадратного сечения 2700х2700 мм. Изоляция выполнена по всему газоходу;

- перед входным газоходом установлен газоплотный запорно-регулирующий клапан;

- входной газоход КУ в виде диффузора, выполненный из листовой углеродистой стали, за байпасным газоходом с компенсатором.

Металлическая обшивка КУ состоит из двух слоев:

- внутренний слой состоит из подвижных пластин, предназначенных для защиты изоляции со стороны дымовых газов;

- наружный (внешний) слой холодный и обеспечивает газоплотность КУ.

Конструкция газоплотной металлической обшивки щитовая с приваренными ребрами жесткости.

Неметаллический компенсатор, расположенный между последним модулем и переходным газоходом к дымовой трубе, прямоугольного сечения с металлическими фланцами для подсоединения на сварке к газоходам котла выполнен из специальных тканевых материалов и предназначен для восприятия радиальных и осевых тепловых расширений, воз-

$$
-229-
$$


никающих из-за разницы температур основного газохода КУ и переходного газохода до дымовой трубы.

Переходной газоход между основным газоходом и дымовой трубой представляет собой короб прямоугольного сечения. Поверхность переходного газохода от КУ до дымовой трубы покрыта наружной изоляцией из базальтового волокна и декоративной обшивкой из оцинкованного листа.

Газоходы КУ опираются на собственные опорные металлоконструкции.

Дымовая труба внутренним диаметром 3300 мм и высотой 60 м установлена непосредственно за котлом в пределах существующего здания.

Изоляция выполнена по всей высоте дымовой трубы. Изоляция дымовой трубы в пределах здания выбрана из условий безопасности рабочего персонала, а изоляция трубы, выходящей за пределы здания, сделана с целью исключения образования конденсата, который может вызвать коррозию в дымовой трубе в зимний период времени.

В дымовой трубе предусмотрены отверстия для установки датчиков давления и температуры, а также газоанализатора.

Отсечной шибер с электроприводом, установленный в средней части дымовой трубы, до подвода байпасного газохода обеспечивает сохранение котла-утилизатора в горячем резерве при остановах.

Водяной тракт КУ состоит из газового подогревателя сетевой воды (ГПСВ), подводящих, перепускных и отводящих трубопроводов.

ГПСВ выполнен в виде одного модуля (2 блока). Каждый блок состоит из секций вертикальных труб с наружным поперечным спирально-ленточным оребрением в сборе с коллекторами, элементов дистанционирования оребренных труб, креплений для подвески секций блоков, потолочной части внутренней и наружной обшивки с тепло- и звукоизоляцией и элементов уплотнений.

Сетевая вода подводится к ГПСВ трубопроводом Ø 325x9 мм, сталь 20 от коллектора подвода воды Ø 377x10 мм, сталь 20, с установленным на нем пружинным предохранительным клапаном. На трубопроводе от сетевых насосов к подводящему коллектору установлена задвижка с электроприводом и запорный клапан на ее байпасе, расходомерное устройство, регулирующий клапан с электроприводом. Из подводящего коллектора к ГПСВ среда подается четырьмя водоподводящими трубопроводами Ø 168х8 мм, сталь 20.

ГПСВ состоит из 812 труб Ø 48х3,5 мм из стали 20, двух раздающих коллекторов Ø 273х20 мм, сталь 20, двух собирающих коллекторов Ø 273х20 мм, сталь 20 и четырнадцати промежуточных коллекторов Ø 108x10 мм, сталь 20. Для полного опорожнения ГПСВ предусмотрены дренажные линии Ø 57x4 мм, сталь 20 с установленной ручной задвижкой на каждой линии и ручной задвижкой на общей дренажной линии Ø 89х6 мм, сталь 20.

В отводящий коллектор Ø 377x10 мм, сталь 20 среда подается трубопроводом Ø 325x9 мм, сталь 20 , в который она поступает по четырем водоотводящим трубопроводам Ø 168x8 мм, сталь 20. На отводящем коллекторе установлен пружинный предохранительный клапан, а также датчики контроля температуры и давления.

Для удаления воздуха из котла-утилизатора предусмотрены линии воздушников Ø 28х3 мм, сталь 20, установленные в верхних точках КУВ. 
В КУВ имеется штуцер для подвода химических реагентов для консервации. Для регулирования температуры сетевой воды перед котлом предусмотрена линия рециркуляции. На линии рециркуляции установлена задвижка с электроприводом.

На отводящем трубопроводе от КУВ установлена задвижка с электроприводом [5].

\section{Заключение}

Анализ работы оборудования энергоблоков 5 и 4 Южно-Сахалинской ТЭЦ-1 показал, что реализация инвестиционных проектов по строительству энергоблоков 4 и 5 с применением газотурбинных установок не только позволила увеличить объем годовой выработки электрической энергии более чем на 57 \% в 2018 г. по сравнению с 2011 г., но и привела к существенному снижению удельного расхода топлива с 360,4 г.у.т/кВт.ч (грамм условного топлива/киловатт*ч) до 325,6 г.у.т/кВт.ч по станции в целом.

Высокие показатели технико-экономической эффективности были достигнуты не только за счет применения высокоэффективных ГТУ, но и за счет оптимизации загрузки всего оборудования ТЭЦ.

Участие оборудования ПСО в базовой части графика с перераспределением тепловой мощности для оптимальной загрузки котлов-утилизаторов 4-го энергоблока позволили достичь снижения показателя удельного расхода топлива на отпущенную тепловую энергию со 149,3 в 2011 г. до 138,8 кг/Гкал в 2018 г.

Достигнутые показатели работы оборудования с 2011 по 2018 г. позволили сэкономить 856,3 тыс. т.у.т., что свидетельствует о высокой экономической эффективности реализованных проектов.

Основным недостатком блоков на базе ГТУ является малый моторесурс по сравнению с ПСО, а также дорогостоящий ремонт.

Нами рассмотрен анализ работы основного и вспомогательного оборудования ТЭЦ «Восточная». Для проведения анализа была собрана и изучена информация по трем водогрейным котлоагрегатам КВ - ГМ - 116,3 - 150, трем газотурбинным установкам LM 6000 PF Sprint, трем водогрейным котлам-утилизаторам КУВ - 46,4 - 130, изучена тепловая и электрическая схема станции, виды и принцип работы насосного оборудования, подогревателей сетевой воды и деаэраторов.

Мы проанализировали принцип работы газомазутных горелочных устройств, устанавливаемых на котлах КВ - ГМ - 116,3 - 150: РГМГ - 30, SAACKE DDZG, циклонно-вихревые предтопки, выявили их достоинства и недостатки.

Составлен анализ отпуска тепловой и электрической энергии за время работы станции, который показал, что с августа 2018 по март 2019 г. станция, работая на природном газе, выработала в общей сумме 626 тыс. Гкал тепловой энергии, при этом за 8 месяцев работы общий расход условного топлива составил почти 94 тыс. т.у.т при максимальной цене на топливо 4560 руб/т.у.т.

Изучена работа по режимно-наладочным испытаниям на котлоагрегатах КВ - ГМ - 116,3 150 № ст. 1-3 при сжигании природного газа, проводимая Хабаровской энерготехнологической компанией. Проанализированы зависимости эксплуатационных, технико-экономических и экологических показателей от нагрузки котлоагрегатов, которые выявили, что наиболее эко-

$$
-231-
$$


номичны режимы работы котлоагрегатов на низких нагрузках $40 \div 55$ Гкал/ч, потери с химическим недожогом во всем диапазоне отсутствуют, а экологические показатели не превышают норму.

\section{Список литературы / References}

[1] ПАО «РусГидро» [Электронный ресурс]. Режим доступа: http://www.rushydro.ru. [PJSC «RusHydro» [Electronic resource]. Access mode: http://www.rushydro.ru (in Russian)]

[2] Паспорт. Стационарная энергетическая газотурбинная установка (ГТУ), тип LM 6000 PF Sprint - General Electric [док. внутреннего пользования]. СП ТЭЦ «Восточная». Владивосток, 2018. 207 с. [Passport. Stationary power gas turbine installation (GTI), type LM6000 PF Sprint General Electric [internal document]. SS HEM «Vostochnaya». Vladivostok, 2018. 207 p. (in Russian)]

[3] Котел водогрейный КВ - ГМ - 116,3 - 150. Руководство по эксплуатации. А - 34025 РЭ - ОАО «Дорогобужкотломаш» [док. внутреннего пользования]: СП ТЭЦ «Восточная». Владивосток, 2014. 22 c. [Hot water boiler BW - GO - 116,3 - 150. Manual. A-34025 RE - OJSC «Dorogobugkotlomash» [internal document] / SS HEM «Vostochnaya». Vladivostok, 2014. 22 p. (in Russian)]

[4] Дорогобужкотломаш [Электронный ресурс]. Режим доступа: http://www.dkm.ru/ [Dorogobugkotlomash [Electronic resource]. Access mode: http://www.dkm.ru/ (in Russian)]

[5] Двухблочная горелка DDZG. Инструкция по эксплуатации - SAACKE GmbH: [док. внутреннего пользования]. СП ТЭЦ «Восточная». Владивосток, 2013. 62 с. [Two-block burner DDZG. Manual - SAACKE GmbH [internal document]. SS HEM «Vostochnaya». Vladivostok, 2013. 62 p. (in Russian)]

[6] Котел-утилизатор водогрейный КУВ-46,4-130 для блока ГТУ-ТЭЦ на площадке ЦПВБ г. Владивосток. Техническое описание. Т620000188 ТО - ОАО «Красный котельщик»: [док. внутреннего пользования]. СП ТЭЦ «Восточная». Владивосток, 2014. 24 с. [Hot water boiler BW-46,4-130 for block GTI-HEM on site CSB c. Vladivostok. Technical description. T620000188 TD - OJSC «Krasnyi kotelschika» [internal document]. SS HEM «Vostochnaya». Vladivostok, 2014. 24 p. (in Russian)] 